\title{
P-205
}

\section{Evaluation of In-Vitro Inhibitory Effect of Malaysian Honey on Human Pathogenic Bacteria}

\author{
Wen-Jie Ng ${ }^{\text {a,b, }}$, Khai-Wei Ken ${ }^{\mathrm{a}}$, Roshani Vijaya Kumar ${ }^{\mathrm{a}}$, Hemamalani Gunasagaran ${ }^{\mathrm{a}}$, Vanaysha \\ Chandramogan ${ }^{\mathrm{a}}$ and Ying-Yee Lee ${ }^{\mathrm{a}}$ \\ ${ }^{a}$ Faculty of Science, Universiti Tunku Abdul Rahman, Perak, Malaysia ${ }^{b}$ Centre for Biodiversity Research, Universiti \\ TunkuAbdul Rahman, Perak, Malaysia; E-mail:ngwj@utar.edu.my
}

Each honey consists of similar nutritional composition but different in its physiochemical content which contains different antibacterial activity due to the differences in its nectar sources. Honey property along with geographical distribution and different floral sources may play important role in the antibacterial activity of honey. The well-diffusion method, minimum inhibitory concentrations (MIC) and minimum bactericidal concentration (MBC) techniques were conducted to investigate the putative antibacterial activity of Tualang (Koompassia excelsa), Gelam (Melaleuca cajuputi) and Durian (Durio zibethinus) honey that were collected from different locations in Malaysia. Honey samples were tested against Staphylococcus aureus ATCC6518 and ATCC25923, Staphylococcus epidermidis ATCC12228, Enterococcus faecium LMG16192, Enterococcus faecalis LMG16216 and ATCC29212, Escherichia coli ATCC25922, Salmonella Typhimurium ATCC14028 and Klebsiella pneumonia ATCC13883. Marked variations were observed in the antibacterial activity of these honey samples. Durian honey failed to produce substantial antibacterial activity, while Tualang and Gelam honey showed a spectrum of antibacterial activity with their growth inhibitory effects against all of the tested bacterial species including vancomycin-resistant enterococci (VRE). Present findings suggested Gelam honey possesses highest antibacterial effect among the tested Malaysian honey samples.

Keywords: Malaysian honey, antibacterial activity, well-diffusion method. 